\title{
Eski Uygur Türkçesinde Farklı Bir Birleşik Zaman Çekimi
}

\section{Beytullah BEKAR1}

\begin{abstract}
$\ddot{O} \mathbf{z}$
Türkçe, tarihi süreç içerisinde ses, şekil ve yapı bakımından çeşitli etkenlere bağlı olarak değişim geçirmiştir. Değişime uğrayan hususlardan biri de fiil çekimlerinde görülmektedir. Orhon Türkçesinde görülen geçmiş zaman eki $-D I$, öğrenilen geçmiş zaman eki $-m I s ̧$, geniş zaman ve şimdiki zaman eki $-A r$, $-I r$ ve $-r$, gelecek zaman eki $-D A c ̧ I$, -çI ve $-s I k$ şeklindedir. Eski Uygur Türkçesinde ise zaman ekleri Orhon Türkçesinden farklllkklar göstermeye başlamıştır. Bu farklllklar hem basit zaman çekimlerinde hem de birleşik zaman çekimlerinde görülmektedir. Eski Uygur Türkçesinde kullanılmış bazı birleşik kipli çekimlerinin Orhon Türkçesinde ve daha sonraki dönemlerde kullanılmadıkları görülmektedir. Bildirimizde Eski Uygur Türkçesi metinlerinde bulunan fakat bu dönemle ilgili gramer çalışmalarının bazılarında geçmeyen birleşik kipli fiil çekimlerine değinilecektir.
\end{abstract}

Anahtar kelimeler: Eski Uygur Türkçesi, fiil çekimi, birleşik zaman.

\section{Conjugation of A Different Kind Compound Tense in Old Uyghur Turkic Language}

\begin{abstract}
Turkish language has changed in terms of phonetic, morphological and syntax becuase of various factors during the historical process. One of the the subjects that has changed during the time is verb conjugations. The simple past tense suffix is $-\mathrm{DI}$, the past tense suffix is $-\mathrm{mIs}$, the simple present tense and present tense suffixes are -Ar, -Ir and -r, the future tense suffixes are -DAçI, -çI and -sIk in Orkhon Turkic Language. It is observed that the temporal suffixes for a verb in Old Uyghur Turkish Language has differentiate from Orkhon Turkic Language. These differences are being seen in both simple tense verb conjugations and compound tense verb conjugations. Also, it can be said that some of the conjugations in compound tense used in Old Uyghur Turkic Language are not used in Orkhon Turkic Language and the languages used in next periods. In this study, we will mention about the compound tense suffixes used in Old Uyghur Turkic Language texts, which are neither seen in grammar works.
\end{abstract}

Key words: Old Uyghur Turkic language, verb conjugations, compound tense.

\section{Giriş}

Türkçede fiiller cümle ve söz içinde diğer kelimelerle çok yönlü ilişkiler kurdukları ve bu ilişkiler dolayısıyla farklı kalıplara girdikleri için dilde yalın olarak değil çekimli olarak bulunurlar. Çekimli bir fiilde de fiil kök ve gövdesi dışında kip, zaman, şahıs sayı kavramı ve ögeleri bulunur (Korkmaz, 2009, s. 567). Fiillerde kip ekleriyle ilgili çok farklı tanımlar ve görüşler bulunmaktadır. Korkmaz Türkiye Türkçesi Grameri Şekil Bilgisi (2009, ss. 567-570) çalışmasında konu ile ilgili farklı görüşlere yer verdikten sonra kip kavramı için; kök veya gövde durumundaki fiilin bildirdiği hareketin, oluş veya

Dr. Öğr. Üyesi Kırklareli Üniversitesi, Fen Edebiyat Fakültesi, Türk Dili ve Edebiyatı Bölümü, beytullahbekar@gmail.com [Makale kayıt tarihi: 3.7.2018-kabul tarihi: 15.8.2018] 
kılışın konuşan, dinleyen veya kendisinden söz edilen açısından ne biçimde, ne tarzda yansıtıldığını gösteren bir gramer kalıbı, bir anlatım biçimidir, der. Bu tanımın ardından Türkiye Türkçesinde bildirme ve haber olmak üzere iki tür fiil kipinin bulunduğunu belirtir.

Fiilde zaman, fiilin bildirdiği oluş veya kılışın zaman çizelgesi içindeki yerini gösteren bir gramer kategorisidir. Bu gramer kategorisi de açıçca belirtilmemiş bir zaman unsurunu taşıyan kipler ve fiilin zamanını gösteren özel ekler olmak üzere iki gruba ayrılır. Zaman eklerinin fiilde bulunuş durumuna göre basit ve birleşik zamanlı olmak üzere iki gruba ayrılır.

Çekimli bir fiil kip ve zaman eklerine ilave olarak şahıs ve sayı eki de alır. Bu ekler bir fiilin gösterdiği oluş ve kılışın hangi şahıslar tarafından yapıldığını bildirirler.

Çalışmamızda ilkin Türkiye Türkçesinde birleşik zamanlı fiil çekimlerine değinilecek ve sonrasında Kemal Eraslan'ın "Eski Uygur Türkçesi Grameri"'; Serkan Şen'in "Eski Uygur Türkçesi Dersleri"; Şahap Bulak'ın "Karşılaştırmalı Tarihî Türk Yazı Dilleri Grameri -Fiil Çekimi-" ve Hacer Tokyürek'in "Eski Türkçede (VIII. YY. - XII. YY.) Yardımcı Fiiller" (Yüksek Lisans Tezi) adlı çalışmalarındaki Eski Uygur Türkçesinde birleşik zaman çekimleri verilecektir. Sonuç bölümünde ise de bu dört eserdeki Eski Uygur Türkçesinde birleşik zaman çekimleri karşılaştırılacaktır.

\section{Türkiye Türkçesinde}

\subsection{Birleşik Kipli Fiil Çekimleri}

Birleşik kipli filler "asıl fiil + şekil zaman eki // i- ek-fiil + şekil zaman eki + şahıs eki2" şeklinde kurulur.

Türkiye Türkçesinde birleşik kipli fiiller hikâye birleşik kipleri, rivayet birleşik kipleri ve şart birleşik kipleri olmak üzere üç gruba ayrılır.

\subsubsection{Birleşik kipli fillerin hikâyesi:}

Bir kip eki almış asıl fiilden sonra i- ek-fiilinin görülen geçmiş zaman ekli şekliyle oluşturulur.

Görülen geçmiş zaman kipinin hikâyesi: asıl fiil + DX // i-ek fiil + DX + şahıs eki asıl fiil + DX + şahıs eki // i-ek fiil DX. Örn.: indiydim indimdi

Öğrenilen geçmiş zaman kipinin hikâyesi: asıl fiil $+m X s ̧ / / i$-ek fiil $+D X+$ şahıs eki. Örn.: inmiştim

Şimdiki zaman kipinin hikâyesi: asıl fiil $+(X)$ yor $\sim m A k t A ~ / / i-e k$ fiil $+D X+$ şahıs eki. Örn.: iniyordum, inmekteydim.

Gelecek zaman kipinin hikâyesi: asıl fiil + AcAk // i-ek fiil + DX + şahıs eki. Örn.: inecektim.

Geniş zaman kipinin hikâyesi: asıl fiil $+r \sim A r \sim X r(-m A z) / / i-e k$ fiil $+D X+$ şahıs eki. Örn.: inerdim.

Şahıs eki yaygın olarak ikinci kip ekine gelmektedir. Fakat bazı istisna kullanımlarda birinci kip ekine geldiği de dörülür. Ayrıntılı bilgi için bakınız: Zeynep Korkmaz, Türkiye Türkçesi Grameri şekil Bilgisi (3. Baskı), TDK Yayınları, Ankara, § $590,2009$. 
Şart kipinin hikâyesi: asıl fiil $+s A / /$ i-ek fiil + DX + şahıs eki. Örn.: inseydim...

İstek kipinin hikâyesi: asıl fiil $+A \sim s A / / i$-ek fiil $+D X+s ̧ a h ı s ~ e k i$. Örn.: ineydim, inseydi.

Gereklilik kipinin hikâyesi: asıl fiil + mAlI // i-ek fiil + DX + şahıs eki. Örn.: inmeliydim.

Emir kipinin hikâyesi: yok

\subsubsection{Birleşik kipli fillerin rivayeti:}

Bir kip eki almış asıl fiilden sonra i- ek-fiilinin öğrenilen geçmiş zaman ekli şekliyle oluşturulur.

Öğrenilen geçmiş zaman kipinin rivayeti: asıl fiil $+m X s ̧ / / i-e k$ fiil $+m X s ̧$ s şahıs eki. Örn.: beklemişmiş.

Şimdiki zaman kipinin rivayeti: asıl fiil $+(X)$ yor $\sim m A k t A / /$ i-ek fiil $+m X s ̧+$ şahıs eki. Örn.: bekliyormuş, beklemekteymiş.

Gelecek zaman kipinin rivayeti: asıl fiil $+A c A k / / i-e k$ fiil $+m X s ̧+$ şahıs eki. Örn.: bekleyecekmiş

Geniş zaman kipinin rivayeti: asıl fiil $+r \sim A r \sim X r(-m A z) / / i-e k$ fiil $+m X s ̧+$ şahıs eki. Örn.: beklermiş.

Şart kipinin rivayeti: asıl fiil $+s A / / i-e k$ fiil $+m X s ̧+$ şahıs eki. Örn.: bekleseymiş̧...

İstek kipinin rivayeti: asıl fiil $+A \sim s A / / i$-ek fiil $+m X s ̧+s ̧ a h ı s ~ e k i$. Örn.: bekleyeymiş, bekleseymiş.

Gereklilik kipinin rivayeti: asıl fiil $+m A l I / / i-e k$ fiil $+m X s ̧+s ̧ a h ı s ~ e k i$ Örn.: beklemeliymiş.

Görülen geçmiş zaman kipinin rivayeti: yok

Emir kipinin rivayeti: yok.

\subsubsection{Birleşik kipli fillerin şartı:}

Bir kip eki almış asıl fiilden sonra i- ek-fiilinin şart kipi şekliyle oluşturulur.

Görülen geçmiş zaman kipinin şartı: asıl fiil + DX // i-ek fiil + sA + şahıs eki asıl fiil + sA + şahıs eki // i-ek fiil DX. Örn.: dediysem dedimse

Öğrenilen geçmiş zaman kipinin şartı: asıl fiil + mXş // i-ek fiil + sA + şahıs eki. Örn.: demişsem.

Şimdiki zaman kipinin şartı: asıl fiil + (X)yor // i-ek fiil + sA + şahıs eki. Örn.: diyorsam.

Gelecek zaman kipinin şartı: asıl fiil + AcAk // i-ek fiil + sA + şahıs eki. Örn.: diyeceksem.

Geniş zaman kipinin şartı: asıl fiil $+\mathrm{r} \sim \operatorname{Ar} \sim \mathrm{Xr}(-\mathrm{mAz}) / / \mathrm{i}-\mathrm{ek}$ fiil $+\mathrm{mX}$ ş + şahıs eki. Örn.: dersem.

Gereklilik kipinin şartı: asıl fiil + mAlI // i-ek fiil + sA + şahıs eki. Örn.: demeliysem.

İstek kipinin şartı: yok. 
Şart kipinin şartı: yok.

Emir kipinin şartı: yok.

\section{Eski Uygur Türkçesinde}

Türk dili tarihinde ‘Eski Uygurca' veya ‘Eski Uygur Türkçesi’ terimleriyle Uygurların Ötüken'den Doğu Türkistan'a, Tarım havzasına indikten sonra Maniheist ve Budist çevrelerde meydana getirdikleri edebiyatın dili kast edilmektedir. Uygurların bu dönemde giriştikleri yoğun tercüme faaliyetleri ile büyük bir dinî, didaktik metin potansiyeli ortaya çıkmıştır (Akar, 2006, s.102).

\subsection{Birleşik Kipli Fiil Çekimleri}

Eski Uygur Türkçesinde birleşik kipli fiil çekimleri Kemal Eraslan, Serkan Şen, Şahap Bulak ve Hacer Tokyürek tarafindan yapılan çalışmalar doğrultusunda dört alt başlıkta incelenecektir.

\subsubsection{Kemal Eraslan, Eski Uygur Türkçesi Grameri (2012)}

Eski Uygur Türkçesinde birleşik zaman çekimlerini hikâye, rivayet ve şart birleşik çekimleri olmak üzere üç alt başlıkta incelemiştir.

2.1.1.1. Hikâye Birleşik Çekimi: Esas fiil herhangi bir kipte, yardımcı er- fiili ise görülen geçmiş zaman kipinde bulunur.

2.1.1.1.1. Geniş Zamanın Hikâyesi: Esas fiil geniş zaman, yardımcı fiil görülen geçmiş zaman kipinde bulunur. Şahıs unsuru yardımcı fiile getirilir. Örn.: Oot öner érti “Ateş yükselir idi.”

2.1.1.1.2. Görülen Geçmiş Zamanın Hikâyesi: Esas fiil görülen geçmiş zaman, yardımcı fiil görülen geçmiş zaman kipinde bulunur. Şahıs unsuru esas ve yardımcı fiile getirilebilir. Örn.: Tülümte men belgülüg körtüm erti bo belgülük "Rüyamda ben bu işareti açıcça gördüm idi."

2.1.1.1.3. Duyulan Geçmiş Zamanın Hikâyesi: Esas fiil duyulan geçmiş zaman, yardımcı fiil görülen geçmiş zaman kipinde bulunur. Şahıs unsuru yardımcı fiile getirilir. Örn.: Taştın ilinçüke önmiş értim. "Dışarıda gezintiye çıkmış idim."

2.1.1.1.4. Gelecek Zamanın Hikâyesi: Esas fiil gelecek zaman, yardımcı fiil görülen geçmiş zaman kipinde bulunur. Şahıs unsuru genellikle esas fiile getirilir: Örn.: Nirvan menğisinğe teggeyler erdi. "Nirvan saadetine erişecekler idi."

2.1.1.1.5. Emrin Hikâyesi: Esas fiil emir kipinde, yardımcı fiil ise görülen geçmiş zaman kipinde bulunur: Örn.: ...yarlkkazun erti "lutfunda bulunsunlar idi."

2.1.1.2. Rivayet Birleşik Çekimi: Esas fiil herhangi bir kipte, yardımcı er- fiili ise duyulan geçmiş zaman kipinde bulunur.

2.1.1.2.1. Geniş Zamanın Rivayeti: Esas fiil geniş zaman, yardımcı fiil duyulan geçmiş zaman kipinde bulunur. Şahıs unsuru yardımcı fiile getirilir. Örn.: Otgurak mini öldürür ermiş. Muhakkak beni öldürmüş imiş. 
2.1.1.2.2. Görülen Geçmiş Zamanın Rivayeti: Esas fiil görülen geçmiş zaman, yardımcı fiil duyulan geçmiş zaman kipinde bulunur. örnek yok

2.1.1.2.3. Duyulan Geçmiş Zamanın Rivayeti: Esas fiil duyulan geçmiş zaman, yardımcı fiil duyulan geçmiş zaman kipinde bulunur. örnek yok

2.1.1.2.4. Gelecek Zamanın Rivayeti: Esas fill gelecek zaman, yardımcı fiil duyulan geçmiş zaman kipinde bulunur. örnek yok

2.1.1.2.5. Şartın Rivayeti. Esas fiil şart kipinde, yardımcı fiil duyulan geçmiş zaman kipinde bulunur: örnek yok

2.1.1.3. Şart Birleşik Çekimi: Esas fiil herhangi bir kipte, yardımcı er- fiili ise şart kipinde bulunur.

2.1.1.3.1. Geniş Zamanın Şartı: Esas fiil geniş zaman, yardımcı fiil şart kipinde bulunur. Örn.: kayu biş yapıglartın çın kirtü nom tözi belgürer erser.. "Hangi beş çeşit tasavvur yığınından hakiki akide esası belirir ise ..."

2.1.1.3.2. Görülen Geçmiş Zamanın Şartı: Esas fiil görülen geçmiş zaman, yardımcı fiil şart kipinde bulunur. Örn.: dintarlarıg ölürtüm erser "dindarları öldürdüm ise...”

2.1.1.3.3. Duyulan Geçmiş Zamanın Şartı: Esas fiil duyulan geçmiş zaman, yardımcı fiil şart kipinde bulunur. Örn.: Kan küçep tiş agrımmış erser, edgü bolgay. "Kan kuvvetlenip diş ağrımış ise, iyi olur."

2.1.1.3.4. Gelecek Zamanın Şartı: Esas fiil gelecek zaman, yardımcı fiil şart kipinde bulunur. Örn.: birök edgü tüşke tegdeçi erser... "Eğer iyi ecre nail olucu ise..."

\subsubsection{Serkan Şen, Eski Uygur Türkçesi Dersleri (2016)}

Eski Uygur Türkçesinde birleşik kipli fiil çekimlerini hikâye, rivayet ve şart birleşik çekimleri olmak üzere üç alt başlıkta incelemiştir. Eser, daha çok öğrencilere yardımcı kaynak olarak hazırlanmış olduğu için Kemal Ersalan'ın eserine göre daha basit ve ayrıntıya yer verilmeden hazırlanmıştır.

\subsubsection{Hikâye Birleşik Çekimi:}

2.1.2.1.1. Geniş Zamanın Hikâyesi: Örn.: kelir er-tim "gelirdim"

2.1.2.1.2. Görülen Geçmiş Zamanın Hikâyesi: Örn.: körtüm er-tim "gördüydüm"

2.1.2.1.3. Öğrenilen Geçmiş Zamanın Hikâyesi: Örn.: tegmiş er-tim "ulaşmıştım”

2.1.2.1.4. Gelecek Zamanin Hikâyesi: Örn.: körgey er-tim "görecektim"

2.1.2.1.5. Emrin Hikâyesi: Oldukça nadir olup esas fiil emir kipinde, yardımcı fiil ise görülen geçmiş zaman çekimindedir. Örnek yok

\subsubsection{Rivayet Birleşik Çekimi:}

2.1.2.2.1. Geniş Zamanın Rivayeti: Örn.: körür er-miş men "görürmüşüm" 
2.1.2.2.2. Görülen Geçmiş Zamanin Rivayeti: Oldukça nadir olup esas fiil görülen geçmiş zaman kipinde, yardımcı fiil ise öğrenilen geçmiş zaman çekimindedir. Örnek yok.

2.1.2.2.3. Öğrenilen Geçmiş Zamanın Rivayeti: Örn.: tıdıl-mış er-miş men "engellenmişmişim”"

2.1.2.2.4. Gelecek Zamanın Rivayeti: Örn.: bar-gay er-miş men "varacakmışım"

\subsubsection{3. Şart Birleşik Çekimi:}

2.1.2.3.1. Geniş Zamanın Şartı: Örn.: tezer er-ser men "kaçarsam"

2.1.2.3.2. Görülen Geçmiş Zamanın Şartı: Örn.: yangıl-tom er-ser "yanıldıysam”

2.1.2.3.3. Öğrenilen Geçmiş Zamanın Şartı: Örn.: küçe-miş er-se men "işkence etmişsem"

2.1.2.3.4. Gelecek Zamanin Şartı: Örn.: bol-gay er-se men "olacaksam"

\subsection{3. Şahap Bulak, Karşılaştırmalı Tarihî Türk Yazı Dilleri Grameri -Fiil Çekimi- (2017)}

Eski Uygur Türkçesinde birleşik kipli fiil çekimlerini diğer üç eserde olduğu gibi hikâye, rivayet ve şart birleşik çekimleri olmak üzere üç alt başlıkta incelemiştir.

\subsubsection{Hikâye Birleşik Çekimi}

2.1.3.1.1. Görülen Geçmiş Zaman Hikâye Birleşik Çekimi: Esas fiil ve ek fiil görülen geçmiş zaman kipinde bulunur. Ek fiil "er-" şeklinde kullanılır. Kişi unsuru esas fiil veya ek fiile getirilir, nadir olarak da hem esas fiill hem de ek fiile getirilir. Örn.: kör-tü-m er-ti "gördüydüm”

2.1.3.1.2. Duyulan Geçmiş Zaman Hikâye Birleşik Çekimi: Esas fiil duyulan geçmiş zaman $-m X s ̧,-y U k$ ve ek fiil görülen geçmiş zaman kipinde bulunur. Ek fiil "er-” şeklinde kullanılır. Kişi unsuru ek fiile getirilir. Örn.: kör-miş er-ti-m "görmüştüm"

2.1.3.1.3. Geniş Zaman Hikâye Birleşik Çekimi: Esas fiil geniş zaman ve ek fiil görülen geçmiş zaman kipinde bulunur. Ek fiil "er-" şeklinde kullanılır. Kişi unsuru ek fiile getirilir. Örn.: kör-ür er-tim "görürdüm"

2.1.3.1.4. Gelecek Zaman Hikâye Birleşik Çekimi: Esas fiil gelecek zaman -gAy ve ek fiil görülen geçmiş zaman kipinde bulunur. Ek fiil “er-" şeklinde kullanılır. Kişi unsuru ek fiile getirilir. Örn.: bar-gay erti-m "varacaktım"

2.1.3.1.5. Emir Kipi Hikâye Birleşik Çekimi: Esas fiil emir kipi ve ek fiil görülen geçmiş zaman kipinde bulunur. Emir ekleri emrin yanı sıra kişi anlamı da taşıdığından çekimde ayrıca kişi unsuru kullanılmaz. Ek fiil "er-" şeklinde kullanılır. Eski Uygur Türkçesi dışında Karahanlı Türkçesine ait metinlerde de emir kipinin hikâye birleşik çekimine örnekler mevcuttur. Örn.: kel-zün er-ti

\subsubsection{Rivayet Birleșik Çekimi}


2.1.3.2.1. Duyulan Geçmiş Zaman Rivayet Birleşik Çekimi: Esas fiil duyulan geçmiş zaman -yUk ve ek fiil duyulan geçmiş zaman kipinde bulunur. Ek fiil "er-" şeklinde kullanılır. Kişi unsuru ek fiile getirilir. Örn.: tüke-yük er-miş men "tükenmişmişim"

2.1.3.2.2. Geniş Zaman Rivayet Birleşik Çekimi: Esas fiil geniş zaman ve ek fiil duyulan geçmiş zaman kipinde bulunur. Ek fiil "er-" şeklinde kullanılır. Kişi unsuru ek fiile getirilir. Örn.: kör-ür er-miş men "görürmüşüm"

\subsubsection{3. Şart Birleşik Çekimi}

2.1.3.3.1. Görülen Geçmiş Zaman Şart Birleşik Çekimi: Esas fiil görülen geçmiş zaman ve ek fiil şart kipinde bulunur. Ek fiil “er-” şeklinde kullanılır. Kişi unsuru esas fiile getirilir. Örn.: kör-tü-m er-ser "gördümse"

2.1.3.3.2. Duyulan Geçmiş Zaman Şart Birleşik Çekimi: Esas fiil duyulan geçmiş zaman $-m X$ ş, ve ek fiil şart kipinde bulunur. Ek fiil "er-" şeklinde kullanılır. Kişi unsuru ek fiile getirilir. Örn.: bol-meş er-ser sen "olmuşsan"

2.1.3.3.3. Geniş Zaman Hikâye Şart Çekimi: Esas fiil geniş zaman ve ek fiil şart kipinde bulunur. Ek fiil "er-" şeklinde kullanılır. Kişi unsuru ek fiile getirilir. Örn.: bul-ur er-ser men "bulursam"

2.1.3.3.4. Gelecek Zaman Şart Birleşik Çekimi: Esas fiil gelecek zaman -DAçI ve ek fiil şart kipinde bulunur. Ek fiil "er-" şeklinde kullanılır. Kişi unsuru ek fiile getirilir. Örn.: kel-teçi er-ser biz.

"geleceksek"

\subsubsection{Hacer Tokyürek, Eski Türkçede (VIII. YY. - XII. YY.) Yardımcı Fiiller (2005)}

Yüksek lisans çalışmasında Eski Uygur Türkçesinde birleşik kipli fiil çekimlerini diğer çalışmalardan farklı olarak ele almıştır. Tokyürek çalışmasında er- yardımcı fiiline getirilen zaman ve kip eklerinden hareket etmemiş asıl fiilin aldığı zaman ve kip eklerine göre sınıflandırmıştır. Bu sebeple birleşik çekimleri geniş zaman, görülen geçmiş zaman, duyulan geçmiş zaman, gelecek zaman, şart ve istek-emir ile yapılan birleşik çekimler altı alt başlıkta incelemiştir.

\subsubsection{Geniş Zaman ile Yapılan Birleşik Kipler}

Uygur Türkçesinde geniş bir kullanıma sahip olan bu yardımcı fiil; geniş zamanın hikâyesini, rivayetini, şartını, geniş zamanını ve zarfını meydana getirir. Bu sahada kullanılan geniş zamanın geniş zaman şekli, zaman fonksiyonundan çok bildirme fonksiyonuyla kullanılmaktadır.

2.1.4.1.1. Geniş Zamanın Hikâyesi: Geniş zamanın hikâyesinin olumlu şekli -Ar er-, -Ir er-, -Ur er-, UrlAr er- şeklindeyken olumsuz şekli ise, -mAz er-, mAzlAr er- şeklinde yapılmaktadır. 3. çoğul çekiminde -lAr eki yardımcı fiile ve asıl fiile de gelebilmektedir. Metinlerde olumlu ve olumsuz şekilleri teklik 1. ve 3., çokluk 1. ve 3. kişilerde görülmüştür. Örn.: bahg taştın tarıgçılarag körür erti “...görürdü”, esirkeyü zglayu tegre tolı tururlar erti “...dururlardı

2.1.4.1.2. Geniş Zamanın Rivayeti: Uygur sahasında er- yardımcı filiyle yapılan rivayet çekimi sadece bir örnekte tespit edilebilmiştir. Geniş zamanın rivayet çekimi -Ur er-şeklinde oluşmaktadır. Sadece 3 . 
teklik şahıs çekimi tespit edilebilmiştir. Örn: anın tẹri kangım sizni okıyur ötünür ermiş “...yalvarırmış"

2.1.4.1.3. Geniş Zamanın Şartı: Geniş zamanın şartının olumlu şekli -r er-, -Ar er-, -Ir er-, -Ur er-, UrlAr er- şekillerindeyken, olumsuz şekli ise -mAz er-, şeklinde yapılmaktadır. Bütün şahıslarda tespit edilemeyen geniş zaman şartı, III. Çoğul şahıs çekiminde çokluk eki er- yardımcı fiilinden önce gelir. Örn.: neteg künteki kararıgı tarkarur erser "...uzaklaştırırsa”

2.1.4.1.4. Geniş Zamanın Geniş Zaman Şekli: Geniş zamanın geniş zaman çekimi -Ur er- ve -mAz erşekillerinde oluşturulmakta olup yüklem görevinde kullanılmaktadır. Örn: bütün edsiz üze tıddaçı ürtdeçi yokındın atı bolur ermez “...adı engelsiz olur.”

2.1.4.1.5. Geniş Zamanın Zarf Şekli: Örn.: Azıgımın tartar erken “Düşmanlarımı tartarken.”

\subsubsection{Görülen Geçmiş Zaman ile Yapılan Birleşik Kipler}

Uygur sahasında görülen geçmiş zaman eki olan -DI eki üzerine er- yardımcı fiili getirilerek birleşik zaman çekimi yapılmaktadır. Er- yardımcı fiili, görülen geçmiş zamanın hikâyesinde, şartında ve geniş zaman çekiminde kullanılmaktadır.

2.1.4.2.1. Görülen Geçmiş Zamanın Hikâyesi: Örn.: Öküş telim tınhglar bultn ertii “...bulduydu”

2.1.4.2.2. Görülen Geçmiş Zamanın Şartı: Örn: Az birip öküş altım erser “...aldım ise”

2.1.4.2.3. Görülen Geçmiş Zamanın Geniş Zaman Şekli: Örn.: polmamakindim erür “...olmayacaktım”

\subsubsection{Duyulan Geçmiş Zaman ile Yapılan Birleşik Kipler}

Uygur sahasında, Göktürk ve Karahanlı sahalarına oranla daha geniş bir kullanım alanına sahip olan duyulan geçmiş zamanın birleşik fiil çekimi, -Mış ve yUk eklerinin üzerine er- yardımcı fiilinin getirilmesi ile oluşturulmaktadır. Bu örneklerin olumlu çekimi, -mIş er- ve -yUk er- şeklindeyken, olumsuz çekimi ise -mAyUk er- şeklinde tespit edilebilmiştir. Uygur sahasında duyulan geçmiş zamanın hikâyesi, rivayeti, şartı ve geniş zaman çekimi kullanılmaktadır.

2.1.4.3.1. Duyulan Geçmiş Zamanın Hikâyesi: Örn.: beşer yüz erin bartp esen tükel kelmiş erti "...gelmişti”

2.1.4.3.2. Duyulan Geçmiş Zamanın Rivayeti: Örn.: adıgh topuzh ārt üze sokuşmiş ermiş “...karşılaşmışlar imiş”

2.1.4.3.3. Duyulan Geçmiş Zamanın Şartı: Örn.: ayıg kılınçlarıg kılgalı uğramış erserler "...uğraşmışlarsa"

2.1.4.3.4. Duyulan Geçmiş Zamanın Geniş Zaman Şekli:Örn.: Belgürmiş erür. "Zuhur etmiştir"

\subsubsection{Gelecek Zaman ile Yapılan Birleşik Kipler}

Uygur sahasında gelecek zamanın hikâye çekimi, -DAçI er-, -gAy er- ve -gU er- şekillerinde yapılır. 
2.1.4.4.1. Gelecek Zamanın Hikâyesi: Örn.: Bergen kagılın tokur tongladaçı erdimiz “...kamçı ile vuracaktık"

2.1.4.4.2. Gelecek Zamanın Rivayeti: Örn.: Bu bizing et’özüg ertimlig ermiş kazganmış ed tavar kaltaçı ermiş “...kalacakmış”

2.1.4.4.3. Gelecek Zamanin Şartı: Örn.: birök edgü tüşke tegdeçiler erser “...ulaşacaklarsa”

2.1.4.4.4. Gelecek Zamanın Geniş Zaman Şekli: Örn: yintem öngre ertmiş üdki savlarıg okıtdaçı erür "...çağıracaktır"

\subsubsection{5. Şart ile Yapılan Birleşik Kipler}

Uygur sahasında şart eki olan -sAr eki üzerine er- yardımcı fiilinin getirilmesiyle birleşik zaman çekimi yapılmaktadır. Geniş zaman çekiminde kullanılmaktadır.

2.1.4.5.1. Şartın Geniş Zaman Şekli: Örn.: Birök körüp yavızıg kodturmasar tıdmasar ermez “...göndermezse/ yasaklamazsa"

\subsubsection{6. İstek-Emir ile Yapılan Birleşik Kipler}

Uygur sahasında istek-emir ekleri olan -AyIn, -zUn, -AlIm ve sUnlAr/-zUnlAr ekleri üzerine eryardımcı fiilinin getirilmesiyle birleşik zaman çekimi yapılmaktadır. Hikâye çekimiyle kullanılmaktadır.

2.1.4.6.1. İstek-Emrin Hikâyesi: Örn.: yir yarlzun erti yirke kireyin erti “...gireydim”

\section{Sonuç}

Her dört araştırmacı tarafından Eski Uygur Türkçesinde birleşik zamanlı fiil çekimleri incelendiğinde şu sonuçlar ortaya çıkmaktadır.

K. Eraslan, Ş. Bulak ve S. Şen tarafından yapılan çalışmada yalnızca hikâye, rivayet ve şart çekimleri verilmişken $\mathrm{H}$. Tokyürek tarafından yapılan çalışmada bunlara ilave olarak er- yardımcı fiiline geniş zaman ekinin getirilmesiyle yapılan birleşik zamanlı fiil çekimi de verilmiştir.

K. Eraslan çalışmasında gelecek zamanın rivayeti ve şartın rivayeti başlıklarını vermiş fakat örnek vermemiştir.

S. Şen çalışmasında emrin hikâyesi ve görülen geçmiş zamanın rivayeti başlıklarını vermiş fakat örnek vermemiştir. Şartın rivayeti başlığı yoktur.

Ş. Bulak çalışmasında öğrenilen geçmiş zamanın, gelecek zamanın ve şartın rivayeti yoktur.

H. Tokyürek çalışmasında diğer üç araştırmacı tarafından değinilmemiş er- yardımcı fiiline geniş zaman ekinin getirilmesiyle yapılan birleşik zamanlı fiil çekimini de vermiştir. Fakat Tokyürek’in çalışmasında ise görülen geçmiş zaman ile şartın rivayeti yoktur. 
Tablo 1. Araştırmacıların Eserlerindeki Birleşik Zamanlı Fiil Çekimlerinin Gösterimi

\begin{tabular}{|c|c|c|c|c|c|c|c|c|c|c|c|c|c|c|c|c|c|c|c|}
\hline & \multicolumn{5}{|c|}{ Hikâye } & \multicolumn{6}{|c|}{ Rivayet } & \multicolumn{3}{|c|}{ Şart } & \multicolumn{5}{|c|}{ Geniş Zaman } \\
\hline & $\begin{array}{l}\dot{N} \\
\stackrel{0}{\Xi} \\
\tilde{J}\end{array}$ & 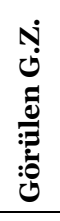 & ك. & $\begin{array}{l}\dot{N} \\
\frac{N}{8} \\
\frac{d}{d} \\
\frac{0}{d}\end{array}$ & 节 & 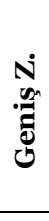 & 造 & 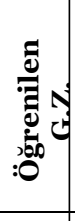 & 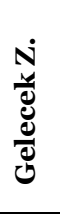 & 莺 & 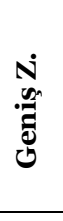 & 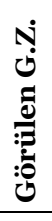 & 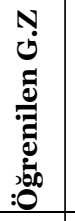 & 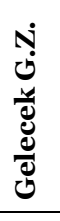 & 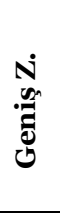 & 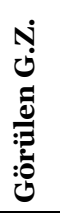 & لئ & 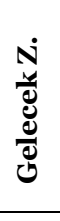 & 䔍 \\
\hline 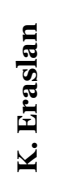 & + & + & + & + & + & + & + & + & 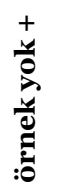 & 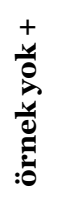 & + & + & + & + & - & - & - & - & - \\
\hline $\begin{array}{l}\text { Dे } \\
\text { के } \\
\text { के }\end{array}$ & + & + & + & + & 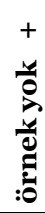 & + & 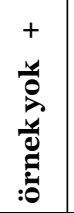 & + & + & - & + & + & + & + & - & - & - & - & - \\
\hline 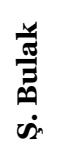 & + & + & + & + & + & + & + & - & - & - & + & + & + & + & - & - & - & - & - \\
\hline 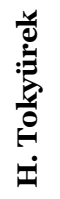 & + & + & + & + & + & + & - & + & + & - & + & + & + & + & + & + & + & + & + \\
\hline
\end{tabular}

\section{Kaynakça}

Barutçu Özönder S. (1998). Üç İtigsizler. Ankara: TDK Yayınları.

Bulak Ş. (2017). Karşılaştırmah Tarihi Türk Yazı Dilleri Grameri -Fïll Çekimi-. İstanbul: Kesit.

Eraslan K. (2012). Eski Uygur Türkçesi Grameri. Ankara: TDK Yayınları.

Erdal M. (2004). A. Grammer of Old Turkic. Leiden Boston.

Ergin M. (1997). Türk Dil Bilgisi. İstanbul: Bayrak.

Ercilasun, A. B. (2009). Başlangıçtan Yirminci Yüzyıla Türk Dili Tarihi. Ankara: Akçă̆ Yayınları.

Gabain A. (1995). Eski Türkçenin Grameri (Çev. Mehmet Akalın). Ankara: TDK Yayınları.

Kaya C. (1994). Uygurca Altun Yaruk Giriş, Metin ve Dizin. Ankara: TDK Yayınları.

Korkmaz Z. (2014). Türkiye Türkçesi Grameri (Şekil Bilgisi). Ankara: TDK Yayınları.

Ölmez M. (2015). Orhon-Uygur Hanlı̆̆ Dönemi Moğolistan'daki Eski Türk Yazıtları. Ankara: BilgeSu Yayınları.

Özmen M. (2003). Gerek, Gerekmek ve Gereklilik Çekimi. Dil ve Edebiyat Araştırmaları Sempozyumu 2003 Mustafa Canpolat Armağanı. Yayımlayanlar: Aysu Ata-Mehmet Ölmez, Ankara: Sanat Kitabevi. ss. 177-193. 
Şen S. (2016). Eski Uygur Türkçesi Dersleri. İstanbul: Kesit Yayınları.

Tekin Ş. (1992). Eski Türkçe. TDEK. Ankara: Türk Kültürünü Araştırma Enstitüsü.

Tekin Ş. (1993). Uygurca Metinler I Kuanşi İm Pusar. Ankara: TDK Yayınları.

Tekin T. (1993). Irk Bitig: The Book of Omens. Wiesbaden: Harrassowitz Verlag.

Tekin T. (1994). Tunyukuk Yazıtı. Ankara: Simug Yayınları.

Tekin T. (2003). Orhon Türkçesi Grameri. İstanbul: Türk Dilleri Araştırmaları Dizisi: 9.

Tekin T. (2010). Orhon Yazıtları. 4. baskı. Ankara: TDK Yayınları.

Tokyürek H. (2005). Eski Türkçede (VIII YY.- XII. YY.) Yardımcı Fïller. Kayseri: Erciyes Üniversitesi Sosyal Bilimler Enstitüsü (Yayımlanmamış Yüksek Lisans Tezi)

Tokyürek H. (2015). Altun Yaruk Sudur IV. Tegzinç. Kayseri: Laçin.(AYS IV.) 